\title{
The effect of a low-frequency sound source (acoustic thermometry of the ocean climate) on the diving behavior of juvenile northern elephant seals, Mirounga angustirostris
}

\author{
Daniel P. Costa ${ }^{\text {a) }}$ \\ Department of Ecology and Evolutionary Biology and the Institute of Marine Sciences, \\ University of California, Santa Cruz, California 95064 \\ Daniel E. Crocker \\ Department of Biology, Sonoma State University, Rohnert Park, California 94928-3609 \\ Jason Gedamke \\ Department of Ocean Sciences and the Institute of Marine Science, \\ University of California, Santa Cruz, California 95064 \\ Paul M. Webb \\ Biology Department, Roger Williams University, One Old Ferry Road, Bristol, Rhode Island 02809 \\ Dorian S. Houser \\ BIOMIMETICA, 5750 Amaya Drive, La Mesa, California 91942
}

Susanna B. Blackwell

Greeneridge Sciences, Inc., 1411 Firestone Road, Goleta, California 93117

Danielle Waples, Sean A. Hayes, and Burney J. Le Boeuf

Department of Ecology and Evolutionary Biology and the Institute of Marine Sciences, University of California, Santa Cruz, California 95064

(Received 4 March 2002; revised 26 July 2002; accepted 20 August 2002)

\begin{abstract}
Changes in the diving behavior of individual free-ranging juvenile northern elephant seals, Mirounga angustirostris, exposed to the acoustic thermometry of the ocean climate (ATOC) sound source were examined using data loggers. Data loggers were attached to the animals and measured swim speed, maximum depth of dive, dive duration, surface interval, descent and ascent rate, and descent and ascent angle along with sound pressure level (SPL). The ATOC sound source was at a depth of $939 \mathrm{~m}$ and transmitted at $195 \mathrm{~dB}$ re: $1 \mu \mathrm{Pa}$ at $1 \mathrm{~m}$ centered at $75 \mathrm{~Hz}$ with a $37.5 \mathrm{-Hz}$ bandwidth. Sound pressure levels (SPL) measured at the seal during transmissions averaged $128 \mathrm{~dB}$ and ranged from 118 to $137 \mathrm{~dB} r e: 1 \mu \mathrm{Pa}$ for the $60-90 \mathrm{~Hz}$ band, in comparison to ambient levels of 87-107 dB within this band. In no case did an animal end its dive or show any other obvious change in behavior upon exposure to the ATOC sound. Subtle changes in diving behavior were detected, however. During exposure, deviations in descent rate were greater than 1 s.d. of the control mean in 9 of 14 seals. Dive depth increased and descent velocity increased in three animals, ascent velocity decreased in two animals, ascent rate increased in one animal and decreased in another, and dive duration decreased in only one animal. There was a highly significant positive correlation between SPL and descent rate. The biological significance of these subtle changes is likely to be minimal. This is the first study to quantify behavioral responses of an animal underwater with simultaneous measurements of SPL of anthropogenic sounds recorded at the animal. (C) 2003 Acoustical Society of America. [DOI: 10.1121/1.1538248]
\end{abstract}

PACS numbers: 43.80.Nd [WA]

\section{INTRODUCTION}

The enhanced transmission of sound and the poor conduction of light in the ocean compel marine mammals to rely heavily on acoustics as their primary sensory modality for many aspects of their life history. Marine mammals produce sounds to transmit information about location, intention, age, sex, reproductive status, and identity of the caller (Thompson et al., 1979; Tyack and Whitehead, 1983; Watkins et al., 1987, 2000; Van Parijs et al., 1999; Tyack and Clark, 2000).

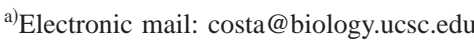

The odontocete cetaceans use high-frequency biosonar to locate prey and to interrogate their environment (Au et al., 1974). Most marine mammal species use passive listening to aid in location of prey, avoidance of predators, and navigation (Tyack and Clark, 2000). Given our understanding of how sound is used by marine mammals, there is reason for concern over the potential impact that anthropogenic noise may have upon them. Human generated underwater noise originates from a variety of sources, but the dominant sources are ship traffic and offshore industrial activities. The 
dominant sources of ship traffic include merchant vessels, icebreakers, naval activities, fishing fleets, and scientific research. Offshore industrial activities include seismic exploration, construction work, drilling, and oil and gas production (Green et al., 1994; Richardson et al., 1995; Gordon and Moscrop, 1996).

An additional, though somewhat infrequent, source of anthropogenic noise comes from oceanographic research. Although high-intensity low-frequency sound (LFS) sources have been used to study the ocean, concern was not raised about the effects of such sound sources on ocean fauna, particularly marine mammals, until the Heard Island Feasibility Test (Munk and Forbes, 1989; Munk et al., 1994). The Acoustic Thermometry of the Ocean Climate (ATOC) experiment was a follow up to the Heard Island study and generated considerable debate (Potter, 1994). ATOC tested the feasibility of using changes in the speed of sound in the ocean measured across long distances $(3000-5000 \mathrm{~km})$ to estimate integrated ocean temperatures (Munk and Forbes, 1989; ATOC Consortium, 1998; Worcester et al., 1999). Achieving this task was done through the introduction of a high intensity, low-frequency sound (broadband source level $195 \mathrm{~dB} r e: 1 \mu \mathrm{Pa}$ at $1 \mathrm{~m}$ ) into the deep sound channel (SOFAR channel) at two locations, off California and Hawaii. In order to determine whether these sounds affected marine mammals, a Marine Mammal Research Program (MMRP) was developed as part of the overall ATOC research program. The overall objective of the MMRP was to determine what species would be exposed to the operational ATOC sound source and assess the effects of that exposure.

The MMRP identified the northern elephant seal, Mirounga angustirostris, as a species of particular concern because these seals naturally migrate past the site of the California ATOC sound source, they are relatively abundant near the source, and they have the best low-frequency hearing capability of any pinniped measured to date (Kastak and Schusterman, 1998). This species is also one of the few marine mammals that frequent the deep sound channel in the northeastern Pacific where the California ATOC source was located (Le Boeuf et al., 2000a). Finally, elephant seals are ideal research subjects for tag-based behavior studies because a wealth of background information exists on their population dynamics, general biology, and at-sea behavior and distribution (Le Boeuf and Laws, 1994).

Recent studies of the free-ranging diving behavior using attached data loggers show that northern elephant seals, $M$. angustirostris, as well as southern elephant seals, $M$. leonina, are consummate divers with few equals in the marine environment (e.g., Le Boeuf et al., 1988; Hindell et al., 1991; Stewart and DeLong, 1991). Northern elephant seals dive continuously, day and night, for periods at sea lasting from 2 to 8 months. They spend $90 \%$ of their time at sea submerged with an average of 20 min per dive (with maximum dive durations of over $1 \frac{1}{2} \mathrm{~h}$ ) followed by less than 3 min at the surface between dives. Northern elephant seals dive to modal depths of 300-600 m with maximum dives exceeding $1500 \mathrm{~m}$. The diving behavior, periods at sea, and migratory paths are known at a general level for juveniles, subadult and adult males, and pregnant and nonpregnant fe- males (Le Boeuf et al., 1996, 2000a). Males travel from California to foraging areas along the continental slope. These foraging areas include the state of Washington north to the upper reaches of the Gulf of Alaska across to the eastern Aleutian Islands. Females disperse more widely across the Northeastern Pacific to as far as $150^{\circ} \mathrm{W}$ (approx. due north of the Hawaiian Islands), in the range $44-52^{\circ} \mathrm{N}$ (DeLong et al., 1992; Le Boeuf et al., 2000a). One-and-a-half-yearold juveniles of both sexes take similar paths as adult females (Le Boeuf et al., 1996). Elephant seals have good hearing within the range of the ATOC sound source (Kastak and Schusterman, 1998) and frequently dive to the deep sound channel. Their long pelagic migrations are also more likely to cause them to be exposed to deep ocean noise as compared to more coastal species.

A significant problem with studying the effect of a particular sound on any animal is identifying the sound pressure level (SPL) to which the animal is exposed. Previous studies have estimated the intensity of sound exposure by correlating the animal's position with empirical measurements or by using model-based predictions of the sound field (Richardson et al., 1995; Au et al., 1997; Frankel and Clark, 1998, 2000; Erbe and Farmer, 2000). Although general features of a lowfrequency sound source can be predicted and/or empirically measured on the large scale, there is much variability at the local scale of an individual animal, including variability in received levels with depth. Previous work has relied on surface measurements of animal location, without data on the animal's depth. The recent development of acoustic data loggers, which can be attached directly to free-ranging animals, allows accurate measurements of the SPL to which the animal is exposed (Fletcher et al., 1996; Burgess et al., 1998).

Simultaneous attachment of instruments that collect information on movements, dive depth and duration, duration at surface, swimming speed, and acoustic exposure enables measurements of received SPLs at the elephant seal to be correlated with simultaneous changes in dive behavior and location (Costa, 1993; Fletcher et al., 1996; Burgess et al., 1998). Changes in these behaviors should reflect the animals' response to the ATOC sound source. For example, if the source were aversive we would predict that animals might respond by spending more time at the surface, making shallower dives, remaining immobile, increasing their ascent rate and velocity when returning to the surface, or in the extreme completely ceasing to dive. Instruments such as data loggers are easily attached to the animals, and attachment to the pelage is secure even after 8 months at sea (Le Boeuf et al., 2000a). Since elephant seals return reliably to the rookery, the instrument recovery rate is high (about $90 \%$ for adults and juveniles) and archival data loggers can be used instead of the more expensive, unrecoverable, and more limited telemetry transmitters that cetacean studies require (Mate et al., 1999). Because these animals are free-ranging, the data gathered by these instruments can provide information on their underwater behavior, allow monitoring at great distances, and provide information that could not be obtained in any other way. 


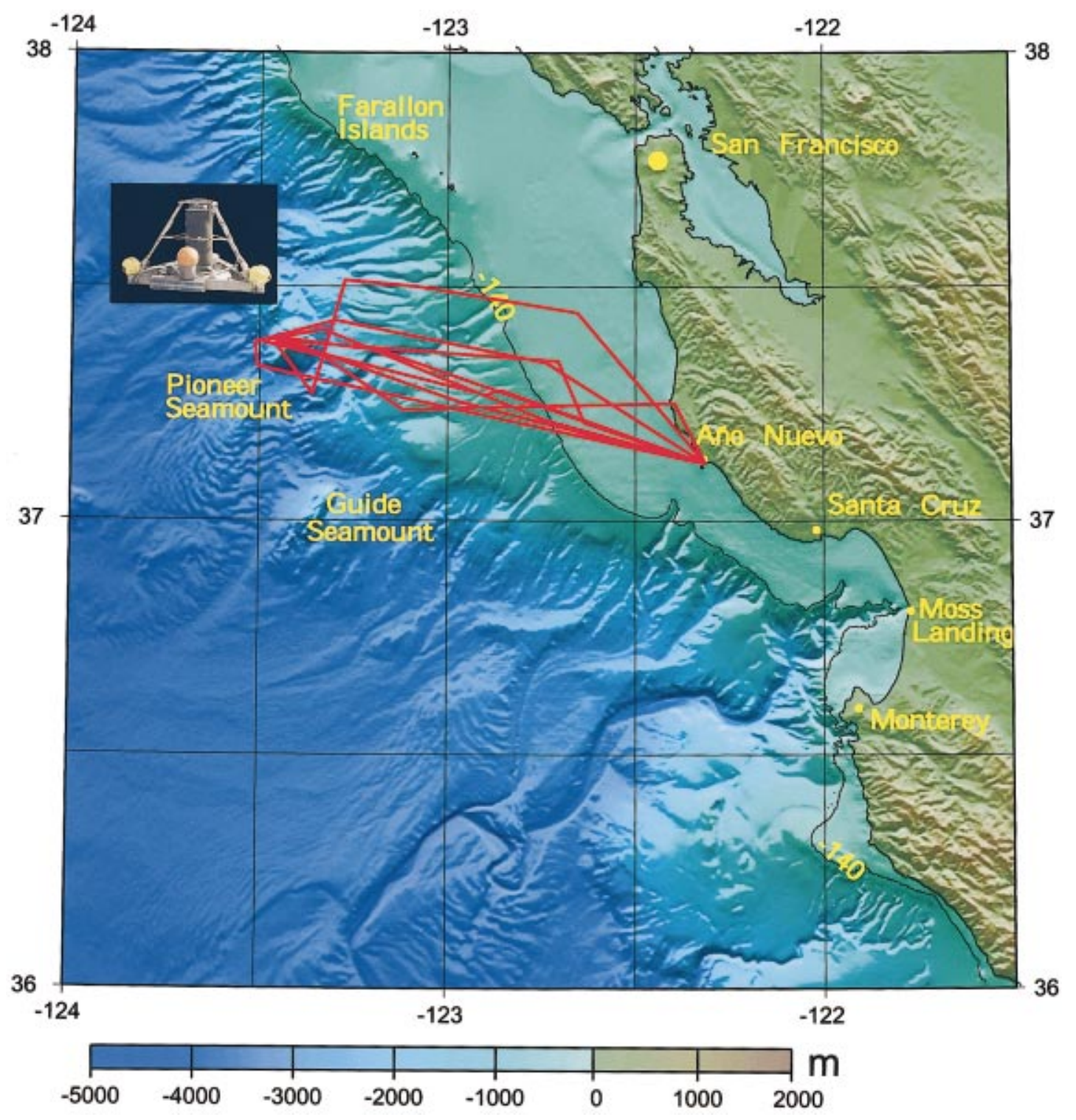

FIG. 1. A chart of the study area is shown with the location of the Pioneer Seamount relative to the Año Nuevo elephant seal rookery 102 kilometers away. The insert is the ATOC sound source. Red lines are representative elephant seal tracks recorded from the ARGOS satellite transmitters. ARGOS locations do not provide precise transit information as only a few locations, of variable quality $(1-10 \mathrm{~km})$, are received each day.

\section{MATERIALS AND METHODS}

\section{A. ATOC sound source}

The ATOC sound source (Alliant Techsystems, HX-554) was deployed in late October 1995 on the PIONEER SEAMOUNT $\left(37^{\circ} 20.555^{\prime} \mathrm{N}, 123^{\circ} 26.7117^{\prime} \mathrm{W}\right), 100 \mathrm{~km}$ west of Half Moon Bay, California, at a depth of $939 \mathrm{~m}$ (Howe, 1996) (Fig. 1). As the focus of this study was to examine the effects of an operational ATOC source, the acoustic power, duty cycle, and frequency used during the trials followed those that would be used for the thermometry studies. The source signal was an M-sequence phase-modulated carrier that consisted of a center frequency of $75 \mathrm{~Hz}$, a bandwidth of $37.5 \mathrm{~Hz}$, and transmitted power of $260 \mathrm{~W}(195 \mathrm{~dB}$ re: $1 \mu \mathrm{Pa}$ at $1 \mathrm{~m}$ ). The M-sequence modulated signal allowed matched filtering to be used to increase the precision of the time of arrival measurements while operating at significantly lower power than would be required without this coding (Munk et al., 1994; Worcester et al., 1999). This coding gives the
ATOC sound source higher bandwidth and thus increases the likelihood of detection by a marine mammal relative to a 75 $\mathrm{Hz}$ pure tone (Au et al., 1997). In an attempt to reduce the effect of the sound source on marine mammals, the source was started at $165 \mathrm{~dB}$ re: $1 \mu \mathrm{Pa}$ at $1 \mathrm{~m}$ and "ramped up" by 6-dB steps each minute for 5 min until reaching and maintaining full power at $195 \mathrm{~dB}$ for $20 \mathrm{~min}$. Transmissions occurred 6 times a day at 4-h intervals for a maximum of 4 days. Ramp up was initiated 5 min prior to the hour, and full power achieved on the hour.

\section{B. Approach}

The response of elephant seals that were captured at the Año Nuevo rookery, translocated, and released beyond the source site was examined experimentally. With the selected protocol, there was a relatively high probability that they would pass over or near the source (i.e., within the 120-dB sound field) in returning to the Año Nuevo rookery. The 
response of these animals to the ATOC sound source was examined using a variety of instruments that provided information on the diving behavior, return track, and the SPL at the animal. ARGOS satellite tags provided information on approximate location at sea. Information on dive behavior was collected using archival tags that, upon recovery, provided the animals' time-marked swim speed and dive depth (STDR) or dive depth alone (TDR). Finally, acoustic data loggers were used to provide information on the animals' ambient acoustic environment as well as the actual SPL of the ATOC signal as received at the animal.

We took advantage of the natural tendency of juvenile elephant seals to return to the site of capture (Oliver et al., 1998) to experimentally expose individuals to the ATOC sound source. These "translocation" animals could be released in such a way that there was a high probability of exposure to the ATOC sound source (Fig. 1). This manipulation had a significant advantage over studies with adult animals because the whole manipulation could be completed in less than 1 week, whereas studies that utilized the natural migration of adults would require at minimum 3.5 months and up to 8 months to complete (Le Boeuf et al., 2000a). Further, we were able to control the distance the animals were released from the source. As we knew that they would return directly to the Año Nuevo rookery, this would increase the probability that they would cross over the source on their return. Moreover, 2-year-old juveniles dive to the same mean depths and exhibit the same mean dive duration as adult males and females (Le Boeuf et al., 1996).

\section{Acoustic data loggers}

Two forms of acoustic data loggers were used. The first was a DAT tag, which consisted of a Sony TCD-D8 digital audio tape recorder (DAT) $(9 \mathrm{~Hz}-16 \mathrm{kHz} \pm 3 \mathrm{~dB})$ enclosed in an aluminum housing $(17.1 \times 12.7 \times 6.7 \mathrm{~cm})$ with an external hydrophone (High Tech, Inc. HT1-SSQ-41b; $10 \mathrm{~Hz}-30 \mathrm{kHz} \pm 3 \mathrm{~dB}$ ) that received the ATOC signal (Fletcher et al., 1996). Units could be turned on either manually with a magnet just prior to release, or the DAT could be programed to automatically turn on approximately $\frac{1}{2}$ hour before animals were released in the water. These units sampled at $32 \mathrm{kHz}$, and recorded for a total of 4-8 hours depending on the tape used. Calibration tones of known rms voltage were recorded onto each tape to allow actual received SPL to be calculated from the recording.

The other instrument was called a compact acoustic probe or CAP tag (Burgess et al., 1998). CAP tags used the same hydrophone as the DAT tag. Within the housing $(36-\mathrm{cm}$ long, 10-cm diameter cylinder) was a programmable Tattletale 7 data acquisition system (Onset Computer Corp., Pocasset, MA) and a 340-MB hard disk. The CAP tags also sampled pressure and temperature. Like the programmable DATs, these units were programed to turn on approximately $\frac{1}{2}$ hour before release. These units were programed to sample at $2000 \mathrm{~Hz}$ and could record for up to 8 days with a frequency response of 10-1000 Hz. The known gain of each step of the digital acquisition process allowed calibrated received SPLs to be calculated.
The DAT and CAP units were recovered after the animals returned to the beach. Acoustic data from the DAT packs were transferred digitally to an SGI workstation, and then low-pass filtered $(4 \mathrm{kHz})$ and resampled $(8 \mathrm{kHz})$ in order to minimize file size. The output sound files and calibration tones were then recorded onto a CD-ROM. Data from the CAP tags were transferred directly from the units to a Macintosh and recorded onto CD-ROM.

\section{Animal manipulation}

We used this experimental system to record the behavior of 29 juvenile (1.8 to 2.4 years old) elephant seals that were instrumented with ARGOS satellite tags and separate data loggers (3 during Fall 1995, 11 during Spring 1996, 11 during Fall 1996, 4 during Spring 1997) and released near the ATOC sound source. Each seal had the following instruments attached to the dorsum: (1) a custom-made swim speed, time-depth recorder (STDR) (B-H Mk1, Santa Cruz, CA) for recording the diving pattern; (2) an acoustic data logger (DAT or CAP); (3) a VHF transmitter (Advanced Telemetry Systems, Isanti, MN) to facilitate recovery of the animals on the rookery; and finally (4) an Argos satellite tag (model ST-6, Telonics, Mesa, AZ) attached to the back of the head to track movements and location (Fletcher et al., 1996; Crocker et al., 1997; Le Boeuf et al., 2000a). The TDRs recorded depth every $10 \mathrm{~s}$ throughout the period at sea. The STDRs recorded relative swim speed every $10 \mathrm{~s}$ using a Logtron paddle wheel (Flash Electronic GmbH, Dachau, Germany) attached to the recorder; revolutions were counted and stored in memory until retrieved. The DATs and CAPs were programed to record continuous low-frequency sounds up to $8 \mathrm{~h}$ and 4 days after release, respectively.

The juveniles were captured at the Año Nuevo rookery and transported by truck to Long Marine Laboratory where they were weighed, measured, and instrumented. Animals were immobilized and instruments attached as previously described (Le Boeuf et al., 1988, 2000a). The following day the seals were transported by ship and released approximately $3 \mathrm{~km}$ due west of the Pioneer SEamount $1 \mathrm{~h}$ prior to activation of the ATOC source. The release site required that seals returning directly to Año Nuevo would travel over the source. Seals were released from this site because, given that pilot studies suggest a horizontal transit rate of approximately $3 \mathrm{~km} / \mathrm{h}$, it maximized the likelihood that seals would cross over the sound source during its 20-25-min period of operation. This protocol was designed to place the animal in close proximity to the ATOC source at activation. In the worst-case scenario, where the seal (unexpectedly) travels west, directly away from the sound source, the protocol would result in animals being approximately $6 \mathrm{~km}$ from the source at activation. A direct line from the drop-off site to the rookery is $105 \mathrm{~km}$. Upon return to the Año Nuevo rookery (3-5 days), the instruments were recovered and data downloaded for analysis.

\section{E. Behavioral analysis}

On recovery, each instrument was calibrated for swimming speed by plotting the rate of depth change against the 


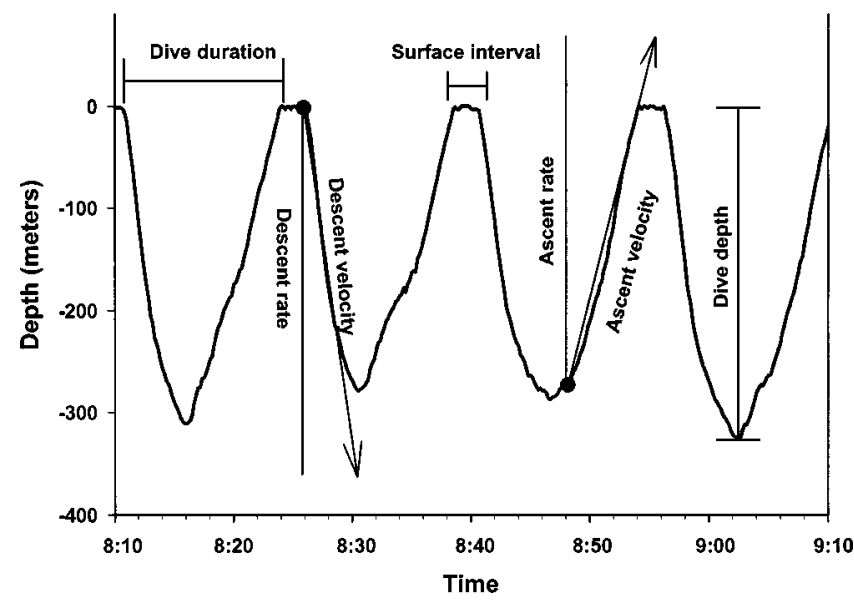

FIG. 2. Section from a typical elephant seal dive record along with the behavioral measurements used to describe the diving pattern.

number of impeller rotations over the same interval (Fletcher et al., 1996; Blackwell et al., 1999). A dive was defined as an excursion below $6 \mathrm{~m}$. The times within dives when descent ended and ascent began were set manually by inspection (Crocker et al., 1997). The following variables were calculated for each recorded dive: maximum depth, duration (start of descent to end of ascent), surface time between dives, descent rate, descent velocity, ascent rate, and ascent velocity (Fig. 2). Ascent and descent rate are measures of the rate that an animal moves vertically through the water column, without respect to any horizontal movement, and calculated as the rate of depth change per unit time. Ascent and descent velocities are measures of the animals' speed, in any direction, while ascending or descending; their velocities are functions of the fluid flow past the seal (Crocker et al., 1997).

We compared the parameters of the dive occurring while the source was on to the mean parameters derived from a control period measured for each animal: an 18 -h period of diving that started $18 \mathrm{~h}$ after the animal was first exposed to the sound source. Each animal was used as its own control to determine whether the behavior measured during the exposure dive fell within 1 or 2 standard deviations of the mean value for the $18 \mathrm{~h}$ of diving where the animal would be beyond the range of the ATOC sound source. Eighteen hours was chosen because all animals spent at least $36 \mathrm{~h}$ transiting over deep water after release from the boat. This allowed the animals $18 \mathrm{~h}$ to swim beyond the seamount and provided 18 $\mathrm{h}$ of data from which to derive a mean diving pattern. Comparisons were made only while the animals were in deep water, since their diving behavior changes when they move over the continental shelf (Le Boeuf and Crocker, 1996). In situations where more than one dive or portions of a dive occurred during exposure, we calculated the responses for the components of the dive that occurred during the exposure period. To account for the potential effect of translocation, a group of seven "control" animals was instrumented with time-depth recorders and satellite tags only and released in the same manner, except the sound source was not operating. The diving records of these animals were analyzed such that the "exposure dive" was assumed to be the dive occurring 1

TABLE I. Absolute and relative (\%) change in behavior (during exposure dive as compared to the 18-h mean for each animal) for 7 dive variables and all 24 subjects, as a function of the maximum ATOC sound-pressure level (SPL) measured at each animal. A negative value would indicate a behavior with a magnitude less than control, for example the depth of dive in animal D9601 was $128 \mathrm{~m}$ shallower. Swim-speed data were not available for animals carrying the CAP tag. Control animals (ATOC source off) were assumed to have the mean measured ambient SPL of $100 \mathrm{~dB} r e: 1 \mu$ Pa. Numbers with an $*$ and in bold are where the exposure dive was greater than \pm 1 s.d. of each animal's $18-\mathrm{h}$ mean. The sex of the animals is given.

\begin{tabular}{|c|c|c|c|c|c|c|c|c|c|c|c|c|c|c|c|}
\hline & \multicolumn{2}{|c|}{ Depth } & \multicolumn{2}{|c|}{ Duration } & \multicolumn{2}{|c|}{ Surface interval } & \multicolumn{2}{|c|}{ Descent velocity } & \multicolumn{2}{|c|}{ Ascent velocity } & \multicolumn{2}{|c|}{ Descent rate } & \multicolumn{2}{|c|}{ Ascent rate } & \multirow{2}{*}{$\frac{\mathrm{SPL}}{\mathrm{dB} r e: 1 \mu \mathrm{P}}$} \\
\hline & Meters & $\%$ & Minutes & $\%$ & Minutes & $\%$ & $\mathrm{~m} / \mathrm{s}$ & $\%$ & $\mathrm{~m} / \mathrm{s}$ & $\%$ & $\mathrm{~m} / \mathrm{s}$ & $\%$ & $\mathrm{~m} / \mathrm{s}$ & $\%$ & \\
\hline D9601 $q$ & $-128 *$ & -31.4 & 1.5 & 6.8 & -0.2 & -8.7 & $0.24 *$ & 20.9 & $-0.21 *$ & -14.5 & 0.38* & 44.7 & $-0.45^{*}$ & -63.4 & 137 \\
\hline D96N2 ชิ & 57 & 15.5 & 2.4 & 13.8 & -0.7 & -17.5 & 0.06 & 4.3 & 0.07 & 4.7 & $0.56 *$ & 76.7 & 0.19 & 29.2 & 135 \\
\hline B961웅 & 60 & 29.3 & 1.5 & 11.6 & -0.1 & -5.3 & -0.14 & -13.0 & -0.21 & -17.9 & $0.31 *$ & 27.4 & -0.02 & -1.6 & 133 \\
\hline D96N1 운 & $-63^{*}$ & -19.5 & $-3.9 *$ & -20.3 & 0 & 0.0 & 0.15 & 11.6 & 0.1 & 8.2 & 0.1 & 14.7 & 0.04 & 5.3 & 132 \\
\hline SOX $q$ & 29 & 9.0 & -2.1 & -12.1 & -0.1 & -3.8 & $0.53 *$ & 54.1 & $-0.38 *$ & -24.5 & $0.51 *$ & 62.2 & 0.1 & 12.3 & 132 \\
\hline CARD $\widehat{\sigma}$ & 81 & 35.2 & -1.7 & -11.3 & -0.7 & -23.3 & $0.32 *$ & 26.9 & 0.12 & 9.6 & $0.68 *$ & 63.6 & -0.01 & -1.0 & 131 \\
\hline MARLIN $\precsim$ & $-82 *$ & -18.7 & -2.6 & -12.0 & 0 & 0.0 & -0.03 & -2.3 & 0.08 & 6.4 & $0.42 *$ & 48.3 & 0.04 & 4.3 & 130 \\
\hline ASTRO q & 3 & 0.8 & -0.2 & -0.9 & 0.4 & 16.7 & 0.11 & 8.9 & -0.02 & -1.5 & 0.09 & 9.4 & -0.09 & -8.7 & 126 \\
\hline CAP962 & -13 & -3.7 & 0.5 & 2.7 & -0.1 & -4.5 & N/A & N/A & N/A & N/A & 0.11 & 11.6 & 0.13 & 14.1 & 126 \\
\hline B962우 & 53 & 26.1 & 1.8 & 13.6 & -0.8 & -26.7 & -0.08 & -7.1 & -0.06 & -5.0 & $0.32 *$ & 34.4 & 0.04 & 4.2 & 124 \\
\hline EXPO & 31 & 10.3 & 0.9 & 5.9 & 0.2 & 11.8 & 0.02 & 2.0 & 0.32 & 24.6 & 0.15 & 15.0 & 0.31 & 46.3 & 124 \\
\hline RED $\sigma$ & 21 & 5.3 & -0.9 & -4.3 & 0.3 & 12.5 & N/A & N/A & N/A & N/A & $0.22 *$ & 25.9 & $0.63^{*}$ & 70.8 & 123 \\
\hline TWIN $\widehat{0}$ & -33 & -11.0 & -4.5 & -20.2 & 0.1 & 4.5 & 0.13 & 11.2 & 0.12 & 12.8 & 0.13 & 12.6 & 0.06 & 7.7 & 121 \\
\hline MET $q$ & -17 & -3.9 & -3.8 & -18.0 & -0.4 & -16.7 & N/A & N/A & N/A & N/A & 0.12 & 14.0 & 0.01 & 1.0 & 118 \\
\hline CUB + & 59 & 24.8 & -1.4 & -9.6 & 0.1 & 7.7 & 0.18 & 14.2 & 0 & 0.0 & 0.08 & 7.5 & 0.14 & 15.7 & N/A \\
\hline D96N3 9 & -6 & -2.2 & -1.2 & -7.4 & 0.3 & 15.8 & 0.11 & 8.7 & -0.09 & -7.1 & $0.46 *$ & 51.7 & -0.02 & -1.8 & N/A \\
\hline D9603 우 & 16 & 8.6 & -1.2 & -8.9 & 0.2 & 11.1 & 0.16 & 12.7 & 0.02 & 1.5 & 0.02 & 2.0 & 0.06 & 5.8 & $\mathrm{~N} / \mathrm{A}$ \\
\hline JENNY & 57 & 22.8 & 2.6 & 15.4 & 0.3 & 17.6 & -0.19 & -12.4 & 0.02 & 1.4 & 0.12 & 13.3 & 0.18 & 15.1 & 100 \\
\hline SALLY & 62 & 27.1 & 4.3 & 33.3 & -0.1 & -5.3 & -0.06 & -4.9 & -0.06 & -4.8 & -0.05 & -4.2 & -0.15 & -12.8 & 100 \\
\hline PIO & -2 & -0.6 & -2 & -8.6 & -0.3 & -13.0 & 0.14 & 11.1 & -0.1 & -6.5 & -0.12 & -9.8 & -0.05 & -4.1 & 100 \\
\hline NEER $q$ & -43 & -11.9 & -4.9 & -24.0 & -0.1 & -3.8 & 0.2 & 20.0 & 0.08 & 6.9 & 0.01 & 0.9 & 0.09 & 9.3 & 100 \\
\hline SEA + & 19 & 5.4 & -1.1 & -6.0 & 0.1 & 5.9 & -0.23 & -15.2 & -0.1 & -7.7 & 0.04 & 4.3 & -0.11 & -10.6 & 100 \\
\hline RIKKI $q$ & 78 & 24.0 & 0.8 & 5.0 & -0.3 & -17.0 & -0.16 & -14.0 & -0.07 & -6.0 & 0.15 & 19.0 & 0.15 & 21.0 & 100 \\
\hline OPRAH & 15 & 4.0 & -1.4 & -7.0 & 0.2 & 10.0 & -0.08 & -6.0 & 0.03 & 3.0 & 0.12 & 14.0 & 0.05 & 6.0 & 100 \\
\hline
\end{tabular}


$\mathrm{h}$ after release from the vessel. As individual animals might respond differently to translocation, we examined the potential effect of translocation on the behavior of each individual animal by comparing the last pre-exposure dive to the mean of all the dives that occurred during the 18-h control period measured for each animal.

\section{F. Acoustic analysis}

Acoustic analysis was carried out using CANARY 1.2 (Cornell University, Ithaca, NY) on a Macintosh 8100 computer. Sound data were calibrated and then examined to exclude sections with high levels of flow noise due to a fast swimming seal. These sound files were bandpass filtered between 60 and $90 \mathrm{~Hz}$ (frequency range of interest) and then mean SPL measurements were made directly from the waveform. Maximum and minimum sound-pressure levels were averaged over a 5-s period. Depths associated with maximum and minimum levels were noted by comparing the time of the sound measurement with the dive record. Ambient levels before and after each ATOC transmission were determined by taking the lowest ambient sound levels received at the animal during the dive directly before and after ATOC transmissions. Lowest levels generally occurred during periods when the animal was not swimming (often during the glide phase of the dive). This provided estimates of ambient noise unaffected by the flow noise caused by swimming. In addition to measurements of SPL we were able to acoustically measure the breathing rate for eight of the animals before, during, and after exposure to the ATOC sound source (Le Boeuf et al., 2000b).

\section{RESULTS}

Data on diving behavior were obtained from 24 animals, 17 of which swam past the ATOC sound source when it was operating on a normal transmission schedule and 7 when the source was not operating at all while the animals were in the water (Table I). Received SPL measurements were obtained for 14 of the animals exposed to the ATOC sound source (Table II). An example of the data collected, including diving pattern and swim speed coupled with acoustic measurements of the ATOC transmission, is provided in Fig. 3. The highest SPLs measured during transmissions ranged from 118 to 137 $\mathrm{dB} r e: 1 \mu \mathrm{Pa}$ for $60-90 \mathrm{~Hz}$ compared to ambient levels of 87-107 dB (60-90 Hz) (Table II). The highest exposure level averaged $128 \mathrm{~dB}$ for all subjects, which gave a mean increase of $29 \mathrm{~dB}$ over ambient SPLs. In no case did an animal end its dive or show any other obvious change in behavior (Fig. 4) in conjunction with a transmission. Other sounds recorded from the seals included a singing humpback whale with a broadband received level of $126 \mathrm{~dB}$ re: $1 \mu \mathrm{Pa}$.

For control animals, the exposure dive was the dive that occurred $1 \mathrm{~h}$ after release from the boat. During the preexposure period, one control animal, NEER, and four experimental animals, D96N1, D9601, RED, and MET had at least one dive parameter that differed by more than one s.d. from the 18-h control period (Table I). Specifically, the control animal NEER exhibited a pre-exposure dive that had a shorter duration and surface interval, with a greater descent
TABLE II. The SPL recorded for each animal before, during and after an ATOC sound transmission is provided. Where available, the depth that corresponded to each SPL measurement is given in parentheses under the SPL measurement.

\begin{tabular}{|c|c|c|c|c|}
\hline \multirow[b]{3}{*}{ Seal } & \multicolumn{4}{|c|}{ Sound-pressure level (dB re: $1 \mu \mathrm{Pa})$} \\
\hline & \multirow{2}{*}{$\begin{array}{l}\text { Prior to ATOC } \\
\text { transmission }\end{array}$} & \multicolumn{2}{|c|}{ During ATOC transmission } & \multirow{2}{*}{$\begin{array}{l}\text { After ATOC } \\
\text { transmissior }\end{array}$} \\
\hline & & Low & High & \\
\hline \multirow[t]{2}{*}{ D96N2 } & 102 & 123 & 135 & 104 \\
\hline & $(430 \mathrm{~m})$ & $(55 \mathrm{~m})$ & $(25 \mathrm{~m})$ & $(289 \mathrm{~m})$ \\
\hline \multirow[t]{2}{*}{ D9601 } & 104 & 126 & 137 & 103 \\
\hline & $(284 \mathrm{~m})$ & $(30 \mathrm{~m})$ & $(24 \mathrm{~m})$ & $(243 \mathrm{~m})$ \\
\hline \multirow[t]{2}{*}{ D96N1 } & 102 & 119 & 132 & 103 \\
\hline & $(216 \mathrm{~m})$ & $(75 \mathrm{~m})$ & $(20 \mathrm{~m})$ & $(268 \mathrm{~m})$ \\
\hline \multirow[t]{2}{*}{ Card } & 105 & 124 & 131 & 103 \\
\hline & $(268 \mathrm{~m})$ & $(71 \mathrm{~m})$ & $(7 \mathrm{~m})$ & $(218 \mathrm{~m})$ \\
\hline \multirow[t]{2}{*}{ Sox } & 102 & 122 & 132 & 104 \\
\hline & $(320 \mathrm{~m})$ & $(68 \mathrm{~m})$ & $(28 \mathrm{~m})$ & $(290 \mathrm{~m})$ \\
\hline \multirow[t]{2}{*}{ Marlin } & 99 & 120 & 130 & 102 \\
\hline & $(355 \mathrm{~m})$ & $(44 \mathrm{~m})$ & $(8 \mathrm{~m})$ & $(347 \mathrm{~m})$ \\
\hline \multirow[t]{2}{*}{ Met } & 87 & 110 & 118 & 89 \\
\hline & & $(323 m)$ & $(67 \mathrm{~m})$ & \\
\hline \multirow[t]{2}{*}{ Red } & 94 & 118 & 123 & 98 \\
\hline & & $(251 \mathrm{~m})$ & $(89 m)$ & \\
\hline \multirow[t]{2}{*}{ Expo } & 99 & 115 & 124 & 97 \\
\hline & & $(112 \mathrm{~m})$ & $(75 \mathrm{~m})$ & \\
\hline \multirow[t]{2}{*}{ Twin } & 95 & 114 & 121 & 93 \\
\hline & & $(2 \mathrm{~m}, 54 \mathrm{~m})$ & $(71 \mathrm{~m})$ & $(110 \mathrm{~m})$ \\
\hline Astro & 98 & 120 & 126 & 96 \\
\hline B961 & 100 & 123 & 133 & 99 \\
\hline B962 & 99 & 115 & 124 & 98 \\
\hline CAP 962 & 98 & 118 & 126 & 99 \\
\hline Mean $=$ & 99 & 119 & 128 & 99 \\
\hline s.d. $=$ & 4.6 & 4.4 & 5.6 & 4.4 \\
\hline
\end{tabular}

velocity, ascent velocity, and descent rate. Among the experimental animals, D96N1 exhibited shorter dive durations, D9601 exhibited a deeper dive and faster descent rate and velocity but a slower ascent velocity and rate, RED exhibited a faster descent rate, and MET exhibited a deeper, shorter dive with a faster descent rate. This implies that the animals had not assumed a normal diving pattern prior to exposure (Fig. 4). Two of these seals, D96N1 and D9601, were only in the water for 31 and 38 min prior to exposure, respectively (Table I, Fig. 4). All other animals exhibited normal diving behavior prior to exposure, and for these animals it was assumed that differences in the exposure dive were due to the operation of the ATOC source. Changes in diving behavior of translocated animals during exposure are provided for each behavioral measure for each animal in Table I. The behavior during exposure dives was within 2 standard deviations of the 18-h mean diving pattern for all animals.

The most sensitive component of diving behavior to ATOC sound transmissions was descent rate. Descent rate changed by more than \pm 1 s.d. from each animal's 18 -h mean in 9 of 14 seals. Dive depth and descent velocity increased by more than \pm 1 s.d. in three animals, ascent velocity decreased in two animals, ascent rate increased in one animal and decreased in another, and dive duration decreased in only one animal. None of the animals showed a deviation by more than \pm 1 s.d. in surface interval. For comparison, $31.7 \%$ of the observations (i.e., about 4 out of 14 animals for 

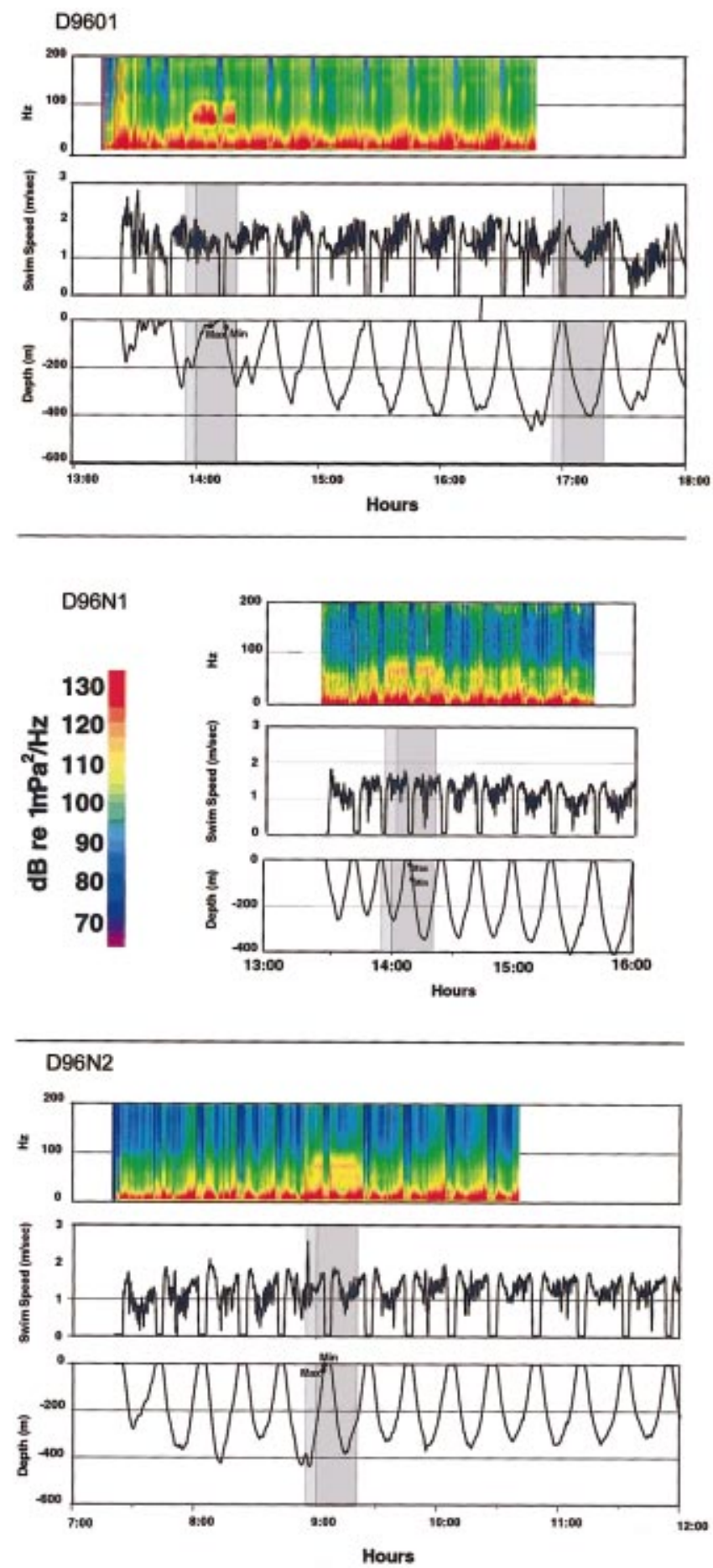

FIG. 3. Three examples of the data collected on juvenile elephant seals that passed near the ATOC sound sources. For each seal the top chart is a sound spectrogram, the middle chart is the swim-speed record, and the bottom chart the time-depth record. The 5-min ramp-up period is shaded in light gray and the 20-min full power operational period in darker gray. The 5-min ramp started $5 \mathrm{~min}$ prior to the hour and full power occurred on the hour. Points on the time-depth record delineate where the various SPL measurements were taken from the spectrogram. For each animal we measured the integrated SPL (while underwater) over the entire period of exposure, along with the maximum and minimum levels (5-s periods). These levels were: integrated 133, max 137, min $126 \mathrm{~dB}$ re: $1 \mu \mathrm{Pa}$ for D9601; integrated 127, $\max 132, \min 119 \mathrm{~dB}$ re: $1 \mu \mathrm{Pa}$ for $\mathrm{D} 96 \mathrm{~N} 1$; and integrated 126, max 135, $\min 123 \mathrm{~dB}$ re: $1 \mu \mathrm{Pa}$ for $\mathrm{D} 96 \mathrm{~N} 2$.
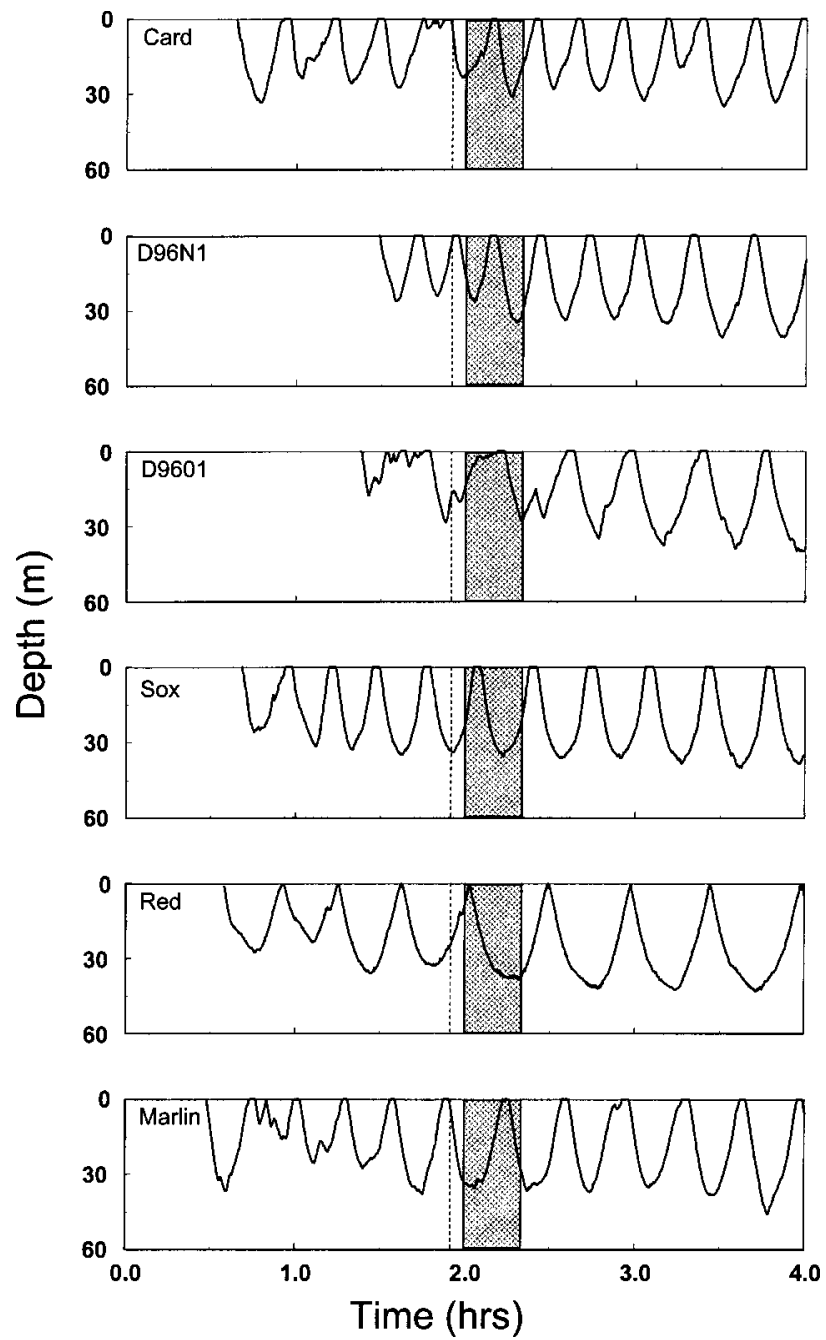

FIG. 4. Dive patterns of the six animals that showed the greatest changes in behavior. The dotted line shows the beginning of the 5-min ramp up and the shaded area shows the period of full power transmission. The first dive corresponds to the animal leaving the boat.

each behavioral measure) would be expected to exceed 1 s.d. for a Gaussian distribution. In only one animal (D96N1) was there a deviation by more than \pm 1 s.d. in depth or duration, without a comparable deviation in descent speed (Table I). There was a highly significant positive correlation between descent rate and SPL (Fig. 5). This correlation was evident whether the animals showing a pre-exposure effect were excluded $\left(r^{2}=0.61, p=0.007\right)$ or included $\left(r^{2}=0.42, p\right.$ $=0.012)$ in the analysis. None of the other variables exhibited a significant correlation between SPL and the deviation from control. There was no significant difference in surface breathing rate for the eight animals for which we were able to obtain these data. The surface-breathing rate was 15.2 \pm 2.0 breaths per minute (BPM) prior to exposure, 17.1 $\pm 3.8 \mathrm{BPM}$ during exposure, and 13.4 $\pm 1.8 \mathrm{BPM}$ after exposure.

Ten of the 17 seals used in the experiment had exposure dives with at least one dive parameter which differed by 

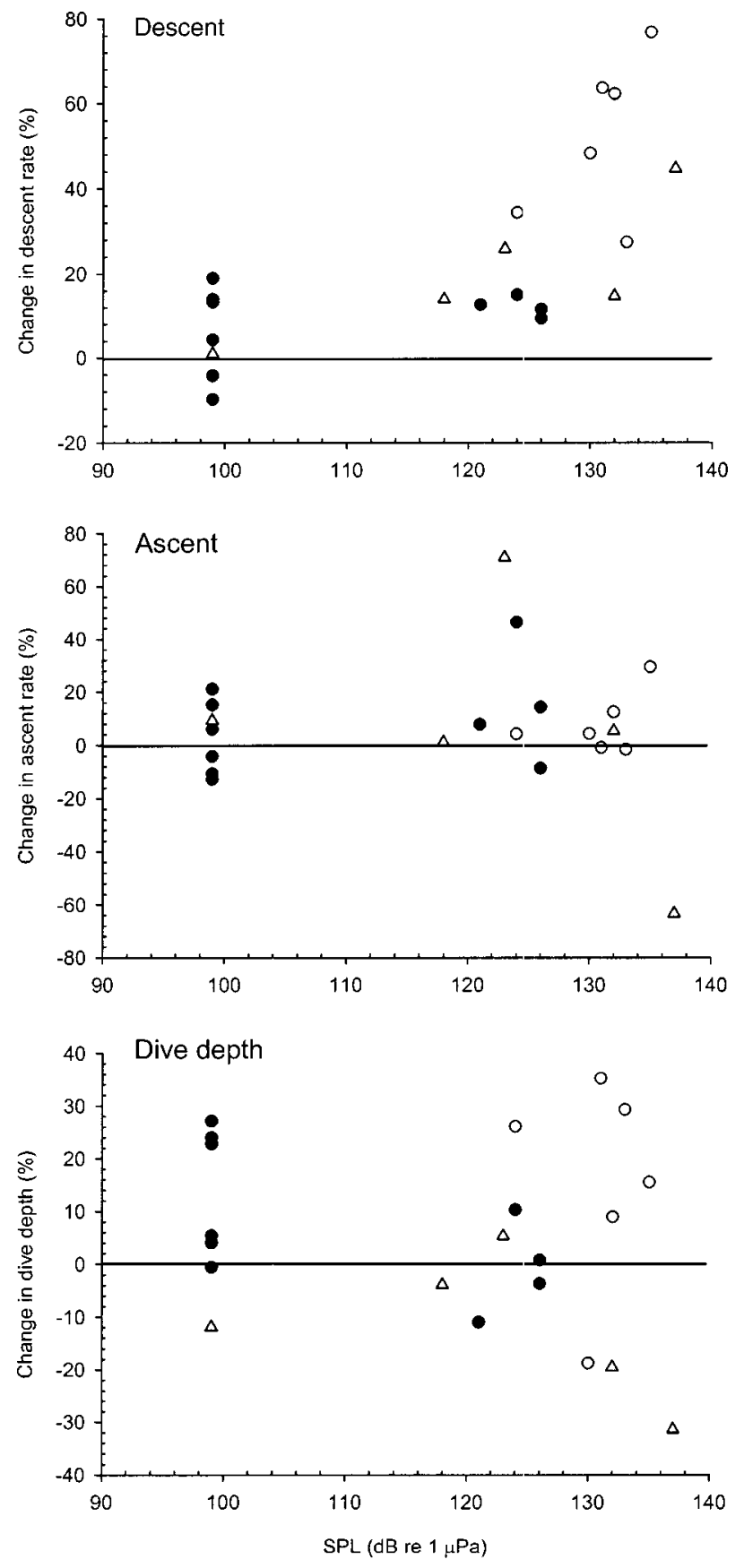

FIG. 5. Relative change in descent rate, ascent rate, and dive depth as a function of the SPL received by the animal, for all subjects used in the translocation studies. Solid symbols represent animals for which the plotted variable during the exposure dive was within \pm 1 s.d. of the 18 -h mean. Open symbols represent animals whose change in ascent rate, descent rate or dive depth was greater than \pm 1 s.d. of the 18 -h mean. Circles designate animals that had a normal pre-exposure dive. Triangles are for animals whose pre-exposure dive varied by more than \pm 1 s.d. from the 18 -h mean. The correlation between change in descent rate and SPL was highly significant regardless of whether animals with a pre-exposure effect were excluded $\left(r^{2}=0.61, p=0.007\right)$ or included $\left(r^{2}=0.42, p=0.012\right)$ in the analysis.

more than \pm 1 s.d. from the 18 -h mean (Table I). The relative number of behavioral parameters that exhibited a deviation greater than \pm 1 s.d. from the 18 -h mean increased as a function of the SPL $\left(r^{2}=0.4, p=0.015\right.$; Fig. 6).

Two approaches were used to look for statistically significant responses using combined data from all of the ani-

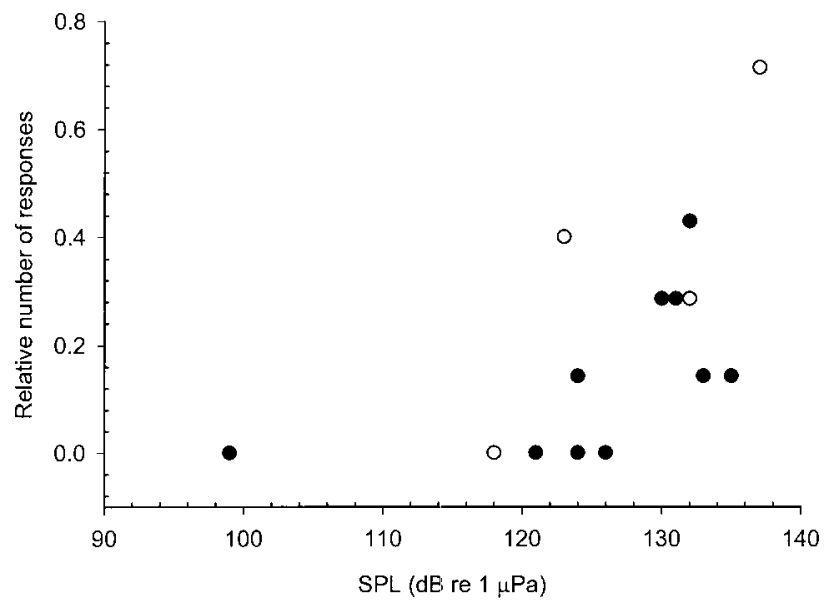

FIG. 6. The relative number of dive variables that varied by more than \pm 1 s.d. from their respective 18 -h means are plotted as a function of the ATOC source SPL as received at the animal. The number of responses was normalized relative to whether there were five or seven variables measured. This was necessary because swim speed was not measured on all animals (those carrying CAP tags). Solid symbols designate animals that had a normal pre-exposure dive. Open circles are for animals that exhibited a preexposure dive with variables that differed by more than \pm 1 s.d. from the 18-h mean. There was a highly significant relationship between these variables $\left(r^{2}=0.4, p=0.015\right)$.

mals. To test for an effect on the exposure dive, repeated measures ANOVA was performed. The dive variables during the exposure dive were compared to the mean values for the 18-h postexposure period for each animal. This approach revealed significant differences between the exposure dives and nonexposure dives in descent rate $\left(F_{1,13}=32.5, p\right.$ $<0.01)$ and descent velocity $\left(F_{1,13}=7.7, p<0.01\right)$. For the control animals (ATOC source off) the dive $1 \mathrm{~h}$ after entry into the water was used as if it were the "exposure dive." This approach yielded no significant differences for the control animals. To examine the effects of the short interval between release and exposure, a similar comparison was made between the exposure dive and the mean values of the pre-exposure period. This analysis revealed no significant differences between pre-exposure and exposure using all of the exposed or control animals. Note that some individual animals did show differences (see Fig. 5).

To test for effects in the hour of diving after exposure using all of the exposure subjects, an ANOVA comparing the hour of postexposure diving to an hour of diving $18 \mathrm{~h}$ after exposure was performed. This ANOVA was run as a general linear model with exposure status (status) and individual (indiv) as effects terms. An interaction term was included in the model (status*indiv) to represent the individual differences in exposure levels. Pseudoreplication was avoided by nesting replicate dives during the hour sampled within the individual animals. The effect of status within this model was tested. This approach revealed significant differences in three of the measured response variables. Descent rate $\left(F_{1,15}=26.0, p\right.$ $<0.01)$ and descent velocity $\left(F_{1,13}=13.8, p<0.01\right)$ were significantly greater in the hour after exposure. Ascent rate was significantly lower during the hour after exposure $\left(F_{1,15}=10.6, p<0.01\right)$. In the control animals (ATOC source off) the second hour of diving after water entry was consid- 
TABLE III. Power analysis $(1-\beta)$ for multiway anova of response variables from a model with exposure status, individual, and (individual $\times$ exposure status) as factors.

\begin{tabular}{lcc}
\hline \hline \multicolumn{1}{c}{ Variable } & Exposure & Control \\
\hline Depth $(\mathrm{m})$ & 0.28 & 0.27 \\
Duration $(\mathrm{min})$ & 1.00 & 0.98 \\
Surface interval $(\mathrm{min})$ & 0.07 & 0.53 \\
Descent speed $(\mathrm{m} / \mathrm{s})$ & 0.96 & 0.87 \\
Ascent speed $(\mathrm{m} / \mathrm{s})$ & 0.86 & 0.67 \\
Total speed $(\mathrm{m} / \mathrm{s})$ & 0.97 & 0.84 \\
Descent rate $(\mathrm{m} / \mathrm{s})$ & 0.93 & 0.87 \\
Ascent rate $(\mathrm{ms})$ & 0.84 & 0.81 \\
\hline \hline
\end{tabular}

ered the postexposure period. No significant differences were evident among the control animals.

To assess the ability to detect significant differences in both exposure and control animals, power analysis was performed for the multiway ANOVA (Table III). This analysis revealed that our sample lacked sufficient power to detect differences in maximum depth and surface interval. For all variables that showed a significant effect in the exposure animals there was sufficient power to detect a difference in the control animals.

\section{DISCUSSION}

There were three major findings with respect to the response of elephant seals to the ATOC sound source. The first was that the highest received level at the animal did not exceed $137 \mathrm{~dB}$ re: $1 \mu \mathrm{Pa}$. This is important, considering that the seals were released so that they would have the highest probability of swimming directly over the ATOC sound source. Second, we did not observe cessation of diving in response to ATOC in any seal studied; and third, we were able to measure only subtle changes in the diving behavior of animals swimming past the ATOC source. With the exception of sperm and beaked whales, elephant seals are the only marine mammal known to be capable of routinely diving to the depth of the ATOC sound projector. This is important considering that SPLs at the seal were always below $137 \mathrm{~dB}$ $r e: 1 \mu \mathrm{Pa}$ and that only 7 out of 14 animals reached maximum exposures at or above $130 \mathrm{~dB}$ re: $1 \mu \mathrm{Pa}$. Given that the experimental manipulation was designed to achieve the highest possible exposure, and that most other species cannot dive like elephant seals, it is likely that they would be exposed to SPLs lower than or at least no greater than those experienced by the elephant seals in this study. Unfortunately, ARGOS satellite uplinks were too infrequent (1-4 per day) and imprecise $(1-10 \mathrm{~km})$ to provide useful information on the return track of the animal. However, some estimate of the proximity of the elephant seals to the sound source can be made by comparison with empirical measurements of the ATOC sound field made with calibrated hydrophones (High Tech, Inc. HT1-SSQ-41b; $10 \mathrm{~Hz}-30 \mathrm{kHz}$ $\pm 3 \mathrm{~dB}$ ) at depths between 50-200 m (Gedamke and Costa, 1997). These data indicate that exposure to $120 \mathrm{~dB}$ re: $1 \mu \mathrm{Pa}$ or greater required the animals to be within $20 \mathrm{~km}$ of the source, while exposure to $130 \mathrm{~dB}$ re: $1 \mu \mathrm{Pa}$ or greater required the animals to be within $4 \mathrm{~km}$ of the source.
In order to put the observed behavioral response in perspective we must consider how an elephant seal might respond to a perceived threat or how it might attempt to "escape" exposure to the ATOC sound source. If an elephant seal perceived the ATOC sound source as a threat, we might find that the seal dove deeper or remained underwater longer. Such a response was recorded for an elephant seal swimming in shallow water as a boat passed overhead (Burgess et al., 1998). This animal stopped swimming and stayed near the bottom as the boat passed overhead. Both northern and southern elephant seals have been observed to undergo prolonged dives that last more than $90 \mathrm{~min}$. These dives are extremely rare, occurring only once or twice over an entire 3-9-month diving record and are not observed in all individuals. It has been suggested that these extremely long dives are a response to the presence of a potential predator like a white shark or killer whale (Le Boeuf and Crocker, 1996). These putative "escape" dives are very distinctive and are several times longer than the typical dive pattern. Similarly, if elephant seals perceived the ATOC sound source as dangerous they might have stopped swimming and extended their dive until the signal ceased. Even juvenile elephant seals are capable of dives lasting longer than the 20min ATOC broadcast. At no time during exposure or at any other time during any dive record did we observe a diving pattern that was even remotely similar to these escape dives. It is important to note that none of these responses was observed in any of the 17 animals exposed to the ATOC sound source.

Although we did not observe obvious changes in the diving behavior of elephant seals, we were able to measure subtler changes. The measure of diving behavior that exhibited the greatest sensitivity to the ATOC sound source was the rate of descent. Rate of descent changed in nine animals and was significantly correlated with SPL (Fig. 5). The corresponding metric ascent rate only changed in two animals, and there was no significant relationship between the change in ascent rate and SPL. However, when the more powerful statistical analysis using the general linear model was carried out, differences in a number of response variables during exposures were detected. Descent rate, descent velocity, and ascent rate all changed in response to exposure or possibly due to the short interval after release. This is consistent with an escape response where the animal prefers to avoid the surface or seeks refuge at depth. Alternatively, if the elephant seal was trying to avoid the ATOC sound source, it could cease diving and remain at the surface and effectively reduce its exposure to the ATOC signal. Within $\frac{1}{4}$ wavelength $(5 \mathrm{~m}$ for a $75-\mathrm{Hz}$ signal) of the ocean surface (pressure-relief surface) the sound level is often 10-30 dB lower (Jensen, 1981). At no time did any seal cease diving or exhibit any other dramatic change in behavior during exposure to the ATOC signal.

It might seem odd that an animal would increase descent rate or decrease its ascent rate when this would prolong its exposure to the sound source. It is necessary to remember 
that this is the predicted antipredator response for this animal. Given the relatively small interaural distance of an elephant seal relative to a $75-\mathrm{Hz}$ signal with a $20-\mathrm{m}$ wavelength, it is unlikely that an elephant seal has the capability of localizing a sound of this frequency and wavelength underwater. Given that the animal may lack information on the location or direction of the sound source, its response may be simply a "startle response," which for elephant seals is to dive.

An alternative explanation of the minimal response observed in northern elephant seals is that they are not capable of hearing the ATOC signal. Recent data on the hearing sensitivity of a captive northern elephant seal indicates a hearing threshold of $98.3 \mathrm{~dB}$ re: $1 \mu \mathrm{Pa}$ for a $75-\mathrm{Hz}$ tone (Kastak and Shusterman, 1998). The peak sensitivity for this animal was $59 \mathrm{~dB}$ re: $1 \mu \mathrm{Pa}$ for a $6300-\mathrm{Hz}$ tone (Kastak and Shusterman, 1998). The mean fundamental frequencies of airborne calls of northern elephant seals are in the range $147-334 \mathrm{~Hz}$ for adult males (Le Boeuf and Petrinovich, 1974) and 500-1000 $\mathrm{Hz}$ for adult females (Bartholomew and Collias, 1962). Furthermore, audiometric studies suggest that pinnipeds in general and elephant seals in particular are relatively good at detecting tonal signals over masking noise (Southall et al., 2000). Given that ambient sound was on average $99 \mathrm{~dB}$ re: 1 $\mu \mathrm{Pa}$ and that the lowest SPL of the ATOC signal as received at the seals' location was $110 \mathrm{~dB}$ re: $1 \mu \mathrm{Pa}$ with an average low of $119 \mathrm{~dB}$ re: $1 \mu \mathrm{Pa}$, we are confident that these animals were capable of hearing the ATOC signal.

To our knowledge this is the first study to quantify behavioral responses of an animal underwater with simultaneous measurements of SPL at the animal. Past studies of the effects of sound on animals have relied on acoustic propagation models and/or measurements of the sound field in the general vicinity of the animal to estimate the level of exposure (Richardson et al., 1990, 1995; Richardson and Würsig, 1997; Würsig et al., 1998; Frankel and Clark, 1998, 2000; Erbe and Farmer, 2000). The problem with this approach is that sound fields are uneven and one can only approximate the sound frequency and intensity to which the animal is exposed. These studies were also limited to measurements such as avoidance of the sound source, changes in respiration rate, fluke pattern, and dive duration. In our study no animal changed its surface interval or respiration rate, and only one animal decreased its dive duration. All of the other behavioral modifications observed here could not have been measured in these previous studies. However, observations of vocal behavior can be carried out while the animal is underwater (Miller et al., 2000), but are still limited by the imprecision of estimates of SPL and animal location.

The Marine Mammal Protection Act makes it illegal to harass or otherwise harm marine mammals in the United States unless a specific authorization has been given. The problem has been in defining what constitutes harassment, and more importantly, defining when that harassment (or the change in behavior as a result of the harassment) impacts sufficient numbers of individuals that it becomes detrimental to the population. As a result of this gray area, there is often a poor link between the laws governing how marine mammals are managed and the actual biological issues underlying those laws. Although we were able to record small changes in the diving behavior of the juvenile elephant seals, it is unlikely that these changes would have any lasting impacts on the animals as they migrate past the ATOC sound source. First, changes in behavior were observed only in animals that were relatively close to the sound source. Second, all elephant seals passing through this area are migrating to or from their distant feeding grounds in the North Pacific Ocean, and thus would not be spending much time near the Pioneer SeAmount (Le Boeuf et al., 2000a). It is important to recognize that although we measured a small change in behavior of migrating animals, the significance of these changes relative to such critical activities as feeding or reproduction is likely to be minimal.

This study has shown the potential for using acoustic data loggers coupled with time-depth recorders to record the response of marine mammals to acoustic stimuli. This approach proved quite effective for use with elephant seals. Further development of the CAP tag is underway (Burgess and Tyack, 2000) and smaller DAT recorders are now available. Smaller devices coupled with recent advances in attachment techniques (Croll et al., 1998; Hooker and Baird, 1999; Nowacek et al., 2001) will allow these techniques to be applied to cetaceans as well as to smaller pinnipeds.

\section{ACKNOWLEDGMENTS}

We thank Chris Clark, Dawn Goley, Don Croll, and Luisa Williams for assistance with the ATOC Marine Mammal Research Program. We especially thank Walter Munk and Peter Worcester for their support throughout the ATOC project. James Ganong and Carl Haverl assisted with data analysis and graphics. John Richardson and an anonymous reviewer provided insightful comments on the manuscript. Clairol Inc supplied bleach or hair dye for marking the seals. The California Department of Parks and Recreation allowed access to Año Nuevo State Reserve. This research was conducted under permit No. 836 from the National Marine Fisheries Service. This work was funded by the Office of Naval Research (ONR N00014-94-1-0455) and the Scripps Institution of Oceanography Acoustic Thermometry of Ocean Climate program via subcontracts from grants ARPA MDA 97293-1-003 and ONR N00014-94-1-0692.

The ATOC Consortium (1998). "Ocean climate change: Comparison of acoustic tomography, satellite altimetry, and modeling," Science 28, $1327-1332$.

Au, W. W. L., Floyd, R. W., Penner, R. H., and Murchison, A. E. (1974). "Measurement of echolocation signals of the Atlantic bottlenose dolphin, Tursiops truncatus Montagu, in open waters," J. Acoust. Soc. Am. 56, 1280-1290.

Au, W. W. L., Nachtigal, P. E., and Pawloski, J. L. (1997). “Acoustic effects of the ATOC signal $(75 \mathrm{~Hz}, 195 \mathrm{~dB})$ on dolphins and whales," J. Acoust. Soc. Am. 101, 2973-2977.

Bartholomew, G. A., and Collias, N. E. (1962). "The role of vocalization in the social behavior of the northern elephant seal," Anim. Behav. 10, 7-14. Blackwell, S. B., Haverl, C. A., Le Boeuf, B. J., and Costa, D. P. (1999). "A method for calibrating swim speed recorders," Marine Mammal Sci. 15, 894-905.

Burgess, W., Tyack, P., Le Boeuf, B. J., and Costa, D. P. (1998). "An intelligent acoustic recording tag: First results from free-ranging northern elephant seals," Deep-Sea Res., Part II 45, 1327-1351. 
Burgess, W., and Tyack, P. (2000). Personal communication.

Costa, D. P. (1993). "The secret life of marine mammals: New tools for the study of their biology and ecology," Oceanography 6, 120-128.

Crocker, D. E., Le Boeuf, B. J., and Costa, D. P. (1997). "Drift diving in female northern elephant seals: Implications for food processing," Can. J. Zool. 75, 27-39.

Croll, D. A., Tershy, B., Hewitt, R., Demer, D., Fiedler, P., Smith, S., Armstrong, W., Popp, J., Kiekhefer, T., Lopez, V., and Urban, J. (1998). "An integrated approach to the foraging ecology of marine birds and mammals," Deep-Sea Res., Part II 45, 1353-1371.

DeLong, R. L., Stewart, B. S., and Hill, R. D. (1992). "Documenting migrations of northern elephant seals using day length," Marine Mammal Sci. 8, 155-159.

Erbe, C., and Farmer, D. M. (2000). "Zones of impact around icebreakers affecting beluga whales in the Beaufort Sea," J. Acoust. Soc. Am. 108, $1332-1340$.

Fletcher, S., Le Boeuf, B. J., Costa, D. P., and Tyack, P. L. (1996). “Onboard acoustic recording from diving elephant seals," J. Acoust. Soc. Am. 100, $2531-2539$.

Frankel, A. S., and Clark, C. W. (1998). "Results of low-frequency playback of M-sequence noise to humpback whales, Megaptera novaeangliae, in Hawaii," Can. J. Zool. 76, 521-535.

Frankel, A. S., and Clark, C. W. (2000). "Behavioral responses of humpback whales (Megaptera novaeangliae) to full-scale ATOC signals," J. Acoust. Soc. Am. 108, 1930-1937.

Green, D. M., DeFerrari, H. A., McFadden, D., Pearse, J. S., Popper, A. N., Richardson, W. J., Ridgway, S. H., and Tyack, P. L. (1994). Low-frequency Sound and Marine Mammals: Current Knowledge and Research Needs (National Research Council, Washington, D.C.)

Gordon, J., and Moscrop, A. (1996). "Underwater noise pollution and its significance for whales and dolphins," in The Conservation of Whales and Dolphins: Science and Practice, edited by M. P. Simmonds and J. D. Hutchinson (Wiley, New York), pp. 281-320.

Hindell, M. A., Slip, D. J., and Burton, H. R. (1991). "The diving behaviour of adult male and female southern elephant seals, Mirounga leonina (Pinnipedia, Phocidae)," Aust. J. Zool. 39, 595-619.

Hooker, S. K., and Baird, R. W. (1999). "Deep-diving behavior of the northern bottlenose whale, Hyperoodon ampullatus (Cetacea: Ziphiidae)," Proc. R. Soc. London, Ser. B 266, 671-676.

Howe, B. M. (1996). "Acoustic Thermometry of Ocean Climate (ATOC): Pioneer Seamount Source Installation,” Tech. Memo. Applied Physics Laboratory-University of Washington, TM 3-96.

Jensen, F. B. (1981). "Sound propagation in shallow water: A detailed description of the acoustic field close to surface and bottom," J. Acoust. Soc. Am. 70, 1397-1406.

Kastak, D., and Schusterman, R. J. (1998). "Low-frequency amphibious hearing in pinnipeds: Methods, measurements, noise, and ecology," J. Acoust. Soc. Am. 103(4), 2216-2228.

Le Boeuf, B. J., and Petrinovich, L. F. (1974). "Dialects in northern elephant seals, Mirounga angustirostris: Origin and reliability," Anim. Behav. 22, 656-663.

Le Boeuf, B. J., Costa, D. P., Huntley, A. C., and Feldkamp, S. D. (1988). "Continuous, deep diving in female northern elephant seals, Mirounga angustirostris," Can. J. Zool. 66, 446-458.

Le Boeuf, B. J., and R. M. Laws. (1994). Elephant Seals: Population Ecology, Behavior and Physiology (University of California, Berkeley), pp. 193-205.

Le Boeuf, B. J., Morris, P. A., Blackwell, S. B., Crocker, D. E., and Costa, D. P. (1996). "Diving behavior of juvenile northern elephant seals," Can. J. Zool. 74, 1632-1644.

Le Boeuf, B. J., and Crocker, D. E. (1996). "Diving behavior of elephant seals: Implications for predator avoidance," in Great White Shark: The Biology of Carcharodon Charcharias, edited by P. Klimley (Academic, San Diego), pp. 193-205.
Le Boeuf, B. J., Crocker, D. E., Costa, D. P., Blackwell, S. B., Webb, P. M., and Houser, D. S. (2000a). "Foraging ecology of northern elephant seals," Ecol. Monogr. 70, 353-382.

Le Boeuf, B. J., Crocker, D. E., Grayson, J., Gedamke, J., Webb, J. M., Blackwell, S. B., and Costa, D. P. (2000b). "Respiration and heart rate at the surface between dives in northern elephant seals," J. Exp. Biol. 203, 3265-3274.

Mate, B. R., Lagerquist, B. A., and Calambokidis, J. (1999). "Movements of north Pacific blue whales during the feeding season off southern California and their southern fall migration," Marine Mammal Sci. 15, 1246-1257.

Miller, P. J. O., Biassoni, N., Samuels, A., and Tyack, P. L. (2000). "Whales songs lengthen in response to sonar," Nature (London) 405, 903.

Munk, W. H., and Forbes, A. M. G. (1989). "Global ocean warming: An acoustic measure?” J. Phys. Oceanogr. 10, 1765-1778.

Munk, W. H., Spindel, R. C., Beggeroer, A., and Birdsall, T. G. (1994). “The Heard Island feasibility test," J. Acoust. Soc. Am. 96, 2330-2342.

Nowacek, D. P., Johnson, M. P., Tyack, P. L., Shorter, K. A., McLellan, W. A., and Pabst, D. A. (2001). "Buoyant balanenids: The ups and downs of buoyancy in right whales," Proc. R. Soc. London, Ser. B 268, 1811-1816.

Oliver, G. W., Morris, P. A., Thorson, P. H., and Le Boeuf, B. J. (1998). "Homing behavior of juvenile northern elephant seals," Marine Mammal Sci. 14, 245-256.

Potter, J. R. (1994). "ATOC: Sound policy or enviro-vandalism? Aspects of a modern mediafueled policy issue," J. Environ. Develop. 3, 47-76.

Richardson, W. J., Greene, C. R. Jr., Malme, C. I., and Thomson, D. H. (1995). Marine Mammals and Noise (Academic Press, San Diego).

Richardson, W. J., and Würsig, B. (1997). "Influences of man-made noise and other human actions on cetacean behavior," Mar. Freshwater Behav. Physiol. 29, 183-209.

Richardson, W. J., Wursig, B., and Greene, C. R. (1990). "Reactions of bowhead whales, Balaena mysticetus, to drilling and dredging noise in the Canadian Beaufort Sea," Mar. Environ. Res. 29, 135-160.

Southall, B. L., Schusterman, R. J., and Kastak, D. (2000). "Masking in three pinnipeds: Underwater, low-frequency critical ratios," J. Acoust. Soc. Am. 108, 1322-1326.

Stewart, B. S., and DeLong, R. L. (1991). "Diving patterns of northern elephant seal bulls," Marine Mammal Sci. 7, 369-384.

Thompson, T. J., Winn, H. E., and Perkins, P. J. (1979). "Mysticete sounds," in Behavior of Marine Animals, Vol. 3: Cetaceans, edited by H. E. Winn and B. L. Olla (Plenum, New York), pp. 403-431.

Tyack, P. L., and Whitehead, H. (1983). "Male competition in large groups of wintering humpback whales," Behaviour 83, 132-154.

Tyack, P. L., and Clark, C. W. (2000). "Communication and acoustic behavior of dolphins and whales," in Springer Handbook of Auditory Research; Hearing by Whales and Dolphins, edited by W. W. L. Au, A. N. Popper, and R. R. Fay (Springer, New York), pp. 156-224.

Van Parijs, S. M., Hastie, G. D., and Thompson, P. M. (1999). "Geographical variation in temporal and spatial vocalization patterns of male harbour seals in the mating season," Anim. Behav. 58, 1231-1239.

Watkins, W. A., Daher, M. A., Reppucci, G. M., George, J. E., Martin, D. L., DiMarzio, N. A., and Gannon, D. P. (2000). "Seasonality and distribution of whale calls in the North Pacific," Oceanography 13, 62-67.

Watkins, W. A., Tyack, P., Moore, K. E., and Bird, J. E. (1987). "The 20-Hz signals of finback whales (Balaenoptera physalus)," J. Acoust. Soc. Am. 82, 1901-1912.

Worcester, P. F., Cornuelle, B. D., Dzieciuch, M. A., Munk, W. H., Howe, B. M., Mercer, J. A., Spindel, R. C., Colosi, J. A., Metzger, K., Birdsall, T. G., and Baggeroer, A. B. (1999). "A test of basin-scale acoustic thermometry using a large-aperture vertical array at $3250-\mathrm{km}$ range in the eastern North Pacific Ocean," J. Acoust. Soc. Am. 105, 3185-201.

Würsig, B., Lynn, S. K., Jefferson, T. A., and Mullin, K. D. (1998). "Behavior of cetaceans in the northern Gulf of Mexico relative to survey ships and aircraft," Aquat. Mam. 24, 41-50. 